\title{
In vivo and in vitro expression of five genes involved in Corynebacterium pseudotuberculosis virulence
}

\author{
Jefferson Ivan Corrêa' ${ }^{1}$ Andreas Stocker ${ }^{3}$, Soraya Castro Trindade ${ }^{2}$, Vera Vale ${ }^{2}$, Thais Brito ${ }^{2}$, Bruno Bastos², \\ José Tadeu Raynal ${ }^{2}$, Patrícia Mares de Miranda², Adriano Costa de Alcantara², Songeli Menezes Freire ${ }^{1,2}$, \\ Lília Moura Costa ${ }^{1,2}$ and Roberto Meyer ${ }^{1,2^{*}}$
}

\begin{abstract}
Caseous lymphadenitis (LC) is a chronic contagious disease caused by Corynebacterium pseudotuberculosis, which mainly affects goats and sheep. Vaccination is an effective but not yet well-established method, partly due to a lack of knowledge surrounding the most effective immunoprotective components. The present study aimed to quantify and compare the in vivo expression of genes pld (phospholipase D), cpp (CP40), nanH (neuraminidase H), sodC (superoxide dismutase C) and spaC (adhesin) using qRT-PCR, with the respective expression in vitro. Caseous material of abscesses removed from five animals was cultured, with colonies suggestive of C. pseudotuberculosis identified. RNA extraction was performed on these samples, as well as on the respective pellets derived from liquid cultures brain heart infusion. After evaluating RNA integrity, complementary DNA was synthesized, followed by the relative quantification each of the genes of interest. Mean mRNA expression of the five genes found in abscesses and in cultures differed significantly, with respective values of: $n a n H 811.50 \pm 198.27$ and $359.35 \pm 75.45$ ( $p=0.009) ;$ cpp $856.31 \pm 385.11$ and 154.54 $\pm 94.34(p=0.0039) ; p I D 922.70 \pm 450.73$ and $212.41 \pm 153.10(p=0.016)$; sodC $1,293.53 \pm 564.75$ and $223.63 \pm 145.58(p=0.016) ;$ spaC $1,157.10 \pm 525.13$ and $214.26 \pm 125.70(p=0,016)$. Expression was observed to be $6-8$ times higher in abscesses than in cultures, Indicative that is a genetic expression of the in vitro bacterium exists, yet in vivo has a greater magnitude corroborating to one of these virulence factors in the pathogenesis of $L C$.
\end{abstract}

Keywords: Corynebacterium pseudotuberculosis, Proteins, Genes, Virulence factor

\section{Introduction}

Caseous lymphadenitis (CL), a chronic contagious disease that affects small ruminants, is caused by Corynebacterium pseudotuberculosis, a gram-positive, pleomorphic, non-sporulated, facultatively anaerobic bacillus belonging to the Corynebacteriaceae family (Actinomycetales order).

The literature is inconsistent with regard to the prevalence of this disease in goat and sheep herds. In Brazilian goats raised in semi-arid areas, studies conducted

\footnotetext{
*Correspondence: r.meyer@ufba.br; meyer.roberto@gmail.com

${ }^{2}$ Laboratório de Imunologia e Biologia Molecular, Instituto de Ciências da Saúde, Universidade Federal da Bahia, Avenida Reitor, Miguel Calmon, S/N, Vale do Canela, Salvador, Bahia CEP 40.110-100, Brazil

Full list of author information is available at the end of the article
}

by Unanian et al. (1985) reported a prevalence of $12 \%$ when sampling animals destined for slaughter (internal abscesses) and $42 \%$ when considering animals used extensively for breeding (superficial abscesses). In Bahia, a prevalence of $55.3 \%$ was observed in sheep of a commercial herd with a flock of 2500 animals (Bastos et al. 2011), as a serum-prevalence of $22.1 \%$ in sheep breeders sampled in agricultural expositions (Nascimento 2012). Another study conducted by Brown et al. (1987) in Brazil found an incidence of $14 \%$ in slaughter animals. In Australia, Batey (1986) found an $8 \%$ incidence of this disease in slaughterhouses. Infection rates ranged from 6.31 to $52 \%$ in sheep inspected at slaughterhouses in Australia, Canada, the United States and Brazil (Batey 1986; Middleton et al. 1991; Arsenault et al. 2003; Stoops et al. 1984; 
Sá et al. 2013; Souza et al. 2011). Meyer (2003), in an extensive serological investigation involving 1966 goats conducted in 19 municipalities throughout the semi-arid zone of the state of Bahia, found highly variable prevalence, with infection rates ranging from 9.2 to $72.2 \%$. Considering that most goat herds are concentrated in the northeastern region of Brazil, together with the fact that these animals are essential for the sustenance of small producers, caseous lymphadenitis poses a relevant threat to the raising of livestock in this region (Meyer 2003).

The strategy to control caseous lymphadenitis is mainly based on vaccination, which has yet to be widely applied throughout the region, in addition to the adoption of complementary measures concerning the inclusion of new animals in herds, early detection of infected animals, segregation, treatment or elimination of diseased animals, special care in routine handling, as well as other measures (Guimarães et al. 2011; Windsor 2011; Kumar et al. 2013).

The immunogenic components of the most effective commercially available vaccines are attenuated live cells of C. pseudotuberculosis, which may be mixed with innocuous forms (toxoids) of phospholipase $\mathrm{D}$, the main virulence factor of C. pseudotuberculosis (Meyer 2003).

Additional virulence factors were proposed following the sequencing of the C. pseudotuberculosis FRC41 genome by Trost et al. (2010). Analysis of the chromosomes in this strain allowed for the identification of several genes highly likely to be involved in virulence, including cpp (CP40), nanH (neuraminidase $\mathrm{H}$ ), rpfA and $r p f B$ (resuscitation-promoting factors $\mathrm{A}$ and $\mathrm{B}$ ), nor (nitric oxide reductase), dtsR2 (acetyl-CoA carboxylase, beta subunit, involved in the biosynthesis of mycolic acid) and spaC (the SpaC protein, a component of adhesin). Although sodC gene was not included in the list of potential virulent factors in the strain sequenced by Trost et al. (2010, p. 10), several researchers consider superoxide dismutase (SodC) to be a virulence factor (Sanjay et al. 2010; Suo et al. 2012). The present study aimed to detect and compare, using quantitative real-time PCR with reverse transcription (qRT-PCR), the in vivo expression of genes pld, cpp, nan $H$ and sodC with expression in vitro. Since bacterial adhesins are virulence factors (Petri et al. 2010) the spaC gene, which synthesizes a protein located at the tip of C. pseudotuberculosis adherent pilli, was also included in the study.

\section{Materials and methods}

\section{Abscess sampling}

Samples were collected from five animals on a farm in the municipality of Jaguarari, Bahia-Brazil, which were diagnosed with caseous lymphadenitis. After removing the wool, the skin covering the lesions suspected of CL was disinfected with $5 \%$ iodized alcohol. Next, a sterilized scalpel was used to make an incision in the lesion, and the caseous content was then collected in a widemouthed sterile flask. Aliquots of approximately $200 \mu \mathrm{L}$ were quickly transferred to cryotubes, which were immediately immersed in dry ice. The remaining caseous material was kept at room temperature. All samples obtained from the animals were transported to the city of Salvador on the same day of collection. The five samples kept on dry ice were rapidly transferred to a freezer and stored at $-80^{\circ} \mathrm{C}$, while the five samples kept at room temperature were sent to the Bacteriology Laboratory at UFBA (the Federal University of Bahia) for culturing and subsequent identification.

\section{Bacteriological analysis}

The five samples submitted to culturing were seeded on sheep blood agar plates and incubated at $37{ }^{\circ} \mathrm{C}$ for 24-48 h. Colonies suggestive of Corynebacterium pseudotuberculosis were identified by colonial morphology, hemolysis pattern analysis, Gram staining and the use of the following biochemical tests: glycose, sucrose, lactose and maltose fermentation, as well as urease and catalase production. Following the identification of C. pseudotuberculosis isolates, samples were cultured placed in $\mathrm{BHI}$ broth containing $0.1 \%$ Tween and incubated at $37^{\circ} \mathrm{C}$ for $48 \mathrm{~h}$. During the exponential growth phase, liquid culture $(500 \mu \mathrm{L})$ was transferred to $1.5 \mathrm{~mL}$ microtubes in triplicate and centrifuged at $4{ }^{\circ} \mathrm{C}$ for $10 \mathrm{~min}$. The supernatants were discarded, while the pellets were stored at $-80{ }^{\circ} \mathrm{C}$ until the time of total RNA extraction.

\section{RNA extractioRNA extraction was performed using a commercially available kit}

RNeasy Mini Kit (Qiagen, Austin, Texas, USA). Cryogenic vials containing approximately $200 \mu \mathrm{L}$ of caseous content or culture pellets previously stored at $-80{ }^{\circ} \mathrm{C}$ were allowed to thaw spontaneously at room temperature. Immediately after, thelysis buffer included in the kit was added to the pellets and, after homogenization, the entire liquid content was transferred to new cryogenic vials containing eight beads of stainless steel. Around 40-50 $\mu \mathrm{g}$ of caseous content were placed in identical cryogenic vials (containing the same amount of beads), followed by the addition of an identical quantity of lysis buffer. The tubes were vertically agitated for $5 \mathrm{~min}$ in a Speedmill homogenizer (Analytic Jena AG) to rupture the bacterial cells. The tubes were then centrifuged at $16,000 \mathrm{~g}$ for $3 \mathrm{~min}$ and the supernatants were transferred to silica columns for RNA recovery. All samples containing abscess material, as well as the respective pellets derived from liquid cultures, were extracted in the same experiment in accordance with the kit manufacturer's 
instructions. Upon termination of the extraction process, $40 \mu \mathrm{L}$ of eluate from each sample were preserved at $-80{ }^{\circ} \mathrm{C}$ until the time of reverse transcription. The DNA extraction of samples containing macrophages infected with C. pseudotuberculosis was performed at the Professor Edgar Santos University Hospital (HUPES) in Salvador-Bahia. These samples were transported in dry ice and immediately transferred to a freezer and kept at $-80{ }^{\circ} \mathrm{C}$ until the time of complementary DNA production.

\section{CDNA production}

cDNA production was performed using $3 \mu \mathrm{g} / \mu \mathrm{L}$ of random hexamers (Invitrogen, Carlsbad, CA, USA) and $200 \mathrm{U} / \mu \mathrm{L}$ of Superscript III Reverse Transcriptase enzyme (Invitrogen, Carlsbad, CA, USA). Briefly, $3 \mu \mathrm{L}$ of eluate obtained from sample extract were added to $5.7 \mu \mathrm{L}$ of ultrapure water with $4 \mu \mathrm{L}$ of dNTPs and $0.80 \mu \mathrm{L}$ of random hexamers. Tubes containing a final volume of $13.5 \mu \mathrm{L}$ of this mixture were placed in a thermal cycler at $95{ }^{\circ} \mathrm{C}$ for 5 min to separate the RNA strands present in the solution. Next, a second mixture was made containing $4 \mu \mathrm{L}$ of First Strand Synthesis Buffer, $1 \mu \mathrm{L}$ of dithiothreitol, $1 \mu \mathrm{L}$ of RNAse inhibitor and $0.5 \mu \mathrm{L}$ of Superscript III RT. After the tubes containing the first mixture were removed from the thermocycler and kept in a freezer at $-4{ }^{\circ} \mathrm{C}$ for $3 \mathrm{~min}, 6.5 \mu \mathrm{L}$ of the second mixture was added to each tube. After annealing was completed, extension was performed as follows: $10 \mathrm{~min}$ at $25{ }^{\circ} \mathrm{C}, 30 \mathrm{~min}$ at $50{ }^{\circ} \mathrm{C}, 15 \mathrm{~min}$ at $53{ }^{\circ} \mathrm{C}$ and $10 \mathrm{~min}$ at $55{ }^{\circ} \mathrm{C}$. Next, reverse transcriptase inactivation was carried out by incubating the tubes at $70{ }^{\circ} \mathrm{C}$ for $15 \mathrm{~min}$. The cDNA product was maintained at $-80^{\circ} \mathrm{C}$ until the time of qPCR to quantify the genes investigated herein.

\section{RNA integrity verification}

Three liquid cultures of C. pseudotuberculosis in exponential growth phase were incubated in BHI with $0.1 \%$ Tween. Following RNA extraction, the three eluates of the samples with higher expression were subsequently submitted to the cDNA protocol described above. To assess RNA integrity, each sample of this material underwent conventional PCR (Taq polymerase, Invitrogen, Foster City, CA, USA) at a final volume of $25 \mu \mathrm{L}$, containing: $15.15 \mu \mathrm{L}$ of ultrapure water, $2.5 \mu \mathrm{L}$ of magnesiumfree buffer $(10 \times) 2.0 \mu \mathrm{L}$ of dNTPs $(4 \times 2.5 \mathrm{mM}), 1.25 \mu \mathrm{L}$ of $\mathrm{MgCl}_{2} 50 \mathrm{mM}, 0.75 \mu \mathrm{L}$ of each of the following primers: Euba-01-F and Uni-R-1492 $10 \mu \mathrm{M}, 0.1 \mu \mathrm{L}$ of Platinum Taq Polymerase $5 \mathrm{U} / \mu \mathrm{L}$ and $2.5 \mu \mathrm{L}$ of cDNA. These mixtures were incubated for $2 \mathrm{~min}$ at $94{ }^{\circ} \mathrm{C}$ in a thermocycler (Eppendorf), and then submitted to 45 staggered cycles as follows: $94{ }^{\circ} \mathrm{C}$ for $20 \mathrm{~s}, 61{ }^{\circ} \mathrm{C}$ for $60 \mathrm{~s}$ and $72{ }^{\circ} \mathrm{C}$ for $60 \mathrm{~s}$, followed by a 4-minute extension at $72{ }^{\circ} \mathrm{C}$.
Electrophoresis was subsequently performed in 1.0\% agarose gel pre-stained with SYBR Safe (Invitrogen, Paisley, UK). In the same gel, a DNA ladder (Invitrogen, Carlsbad, CA, USA) containing 100-2000 base pairs was added. Photographic documentation was employed to verify the presence of a $1492 \mathrm{bp}$ band.

\section{qPCR}

Paired mRNA quantification with respect to each gene studied was performed by loading a thermocycler with optical tubes of either abscess samples or cultures of abscesses obtained from the same animals. Accordingly, 5 abscess samples and 5 culture samples were analyzed to compare the expression of the five genes encoding virulence factors and the 16S RNA housekeeping gene. All reactions were performed at a final volume of $25 \mu \mathrm{L}$ containing: $7.4 \mu \mathrm{L}$ of RNase-free water, $12.5 \mu \mathrm{L}$ of Power SYBR Green Master Mix (2X) (Applied Biosystems), $1 \mu \mathrm{L}$ of Bovine Serum Albumin $(1 \mathrm{mg} / \mathrm{mL}), 0.75 \mu \mathrm{L}$ of $10 \mu \mathrm{M}$ forward primers and $0.75 \mu \mathrm{L}$ of $10 \mu \mathrm{M}$ of reverse primers, $0.1 \mu \mathrm{L}$ of Platinum Taq Polymerase enzyme $(5 \mathrm{U} / \mu \mathrm{L})$ and $2.5 \mu \mathrm{L}$ of cDNA eluates.

The primers utilized are shown in Fig. 1 Primer pairs were designed using the Primer Quest tool found on the Integrated DNA Technologies-ITD website, (http://www. idtdna.com/site). Seven pairs of primers were chosen for sequences ranging in size between 250 and 300 base pairs in order to standardize the dissociation temperatures to approximately $63{ }^{\circ} \mathrm{C}$, allowing all qPCR reactions to be performed in a single round (Fig. 1).

Target amplification was performed using an ABI Prism 7500 thermocycler (Applied Biosystems) under the following time and temperature conditions: initial denaturation for $10 \mathrm{~min}$ at $95{ }^{\circ} \mathrm{C}$, followed by 45 cycles of denaturation for $20 \mathrm{~s}$ at $94{ }^{\circ} \mathrm{C}$ and annealing for $60 \mathrm{~s}$ at $62{ }^{\circ} \mathrm{C}$. The result of each qPCR amplification was evaluated by analyzing the dissociation curve (melting curve).

\section{mRNA quantification}

Virulent Corynebacterium pseudotuberculosis in exponential growth phase was cultured (BHI broth with $0.1 \%$ Tween), then homogenized and centrifuged at $6000 \mathrm{~g}$ for 5 min at $4{ }^{\circ} \mathrm{C}$, after which the supernatant was discarded. The pellet was preserved in a freezer at $-80{ }^{\circ} \mathrm{C}$ and nucleic acids were extracted using a commercially available RNeasy Mini Kit (Qiagen). The eluate $(40 \mu \mathrm{L})$ was aliquoted and used for cDNA production, in accordance with procedures described above. Six serial dilutions were prepared with ultrapure water for PCR, with cDNA ranging from $10^{-1}$ to $10^{-6}$. The original solution and all six dilutions were frozen at $-80^{\circ} \mathrm{C}$ until the quantitative reactions were performed. For each of these dilutions, six amplifications were performed using specific primers for 


\begin{tabular}{lll}
\hline Gene & Sentido & Sequência dos Primers \\
\hline$C p p$ & Forward & 5'-ACG GTA GGC ATA ACT TCC GCT CTT-3' \\
& Reverse & 5'-TCA GCT TGA CCT GGA GCT TGT CTT-3' \\
plD & Forward & 5'-TGG AAC CTG GAA TCG GAC TTG TGA-3' \\
& Reverse & 5'-TTA TCC ACC CAC CTC TTG ATG GCT-3' \\
ngnH & Forward & 5'-TGG CTA AGG CTA TTG AAG ACG CGA-3', \\
& Reverse & 5'-AAT CGT AGC TCC CTC AGC TGC TTT-3' \\
kngl6S & Forward & 5'-AGT AAC TGA CGC TGA GGA GCG AAA-3' \\
& Reverse & 5'-CAG GTA AGG TTC TTC GCG GTT GCA T-3' \\
pkng & Forward & 5'-AGC AGA TAT TAC GCA CCC GGG AAT-3' \\
& Reverse & 5'-TTA CCT GGT CCT CGG CAA CAA TGA-3' \\
sodC & Forward & 5'-TTG TCG CGG CCT TCA TGA ACA ATC-3' \\
& Reverse & 5'-CCA TGG CTT CCA CGT TCA TGA CAA-3' \\
spaC & Forward & 5'-AAG CCG TCA ACC GAC TAC CGT TTA-3' \\
& Reverse & 5'-AAT TCA AAC CGG TAG GAG CCA GGA-3' \\
\hline
\end{tabular}

The primers used were Euba-01-F (reverse) and Uni-1492-R (reverse), designed

for a well-conserved 1492 base pairs for $16 \mathrm{~S}$ ribosomal RNA from eubacteria

Fig. 1 Primers used in the experiments

each of the five genes studied (see Table 1) plus another pair of primers for the $16 \mathrm{~S}$ ribosomal RNA gene, used as a control for being one of the genes most used in studies of bacterial gene expression (Carvalho et al. 2014). After qPCR, linear regression analysis was applied to generate a calibration curve for each of the genes.

For relative DNA quantification (and, by extension, mRNA), a quantification value was determined for each of the six genes studied as follows: quantification factor $=10^{\mathrm{W}}$, in which $\mathrm{w}=$ [linear coefficient $-(\mathrm{Ct} \times$ angular coefficient)]. By dividing the values of the quantization factors corresponding to each genes by the respective values of the housekeeping gene, we obtained the relative expression values of the studied genes. Finally, the ratio of abscess values/culture was calculated to indicate the number of times a particular gene was more highly expressed in an abscess.

\section{Statistical analysis}

The Mann-Whitney test was used to compare the expression of each gene in culture with expression in abscesses. The relative expression of each gene in each of the five animals was compared using the Kruskal-Wallis test. $\mathrm{p}$ values $<0.05$ were considered significant.

\section{Results \\ Quality assessments of RNA extraction and CDNA production}

Figure 2 depicts the $1.0 \%$ agarose gel used to verify the quality of the amplicons produced by conventional PCR following RNA extraction and cDNA production from three different samples containing a virulent strain of $C$. pseudotuberculosis.

The DNA ladder varies between 100 and 2000 base pairs (bp), with greater visibility seen on 2000, 1500 and $600 \mathrm{bp}$. Three bands were seen around $1500 \mathrm{bp}$, characterizing the amplicon with $1492 \mathrm{bp}$, demonstrating the suitability of the protocols used in this study for the extraction and efficient production of cDNA by real-time PCR.

\section{Gene expression in vitro and in vivo}

With respect to messenger RNA synthesis, all of the genes evaluated had in vitro expression. Table 1 shows the quantification of rRNA16S, nanH, cpp, pld, sodC, and spaC genes in abscesses and their respective cultures, corresponding normalization indices and expression ratios of abscesses compared to cultures. These same genes were also expressed in vivo, but with greater intensity. 
Table 1 Relative quantification and exression multiplicity of nanH, cpp, pld, sodC and spaC genes from Corynebacterium pseudotuberculosis

\begin{tabular}{|c|c|c|c|c|c|c|}
\hline Sample & mRNA & $\begin{array}{l}\text { Quantification fator } \\
\text { in the abscess }\end{array}$ & $\begin{array}{l}\text { Quantification fator } \\
\text { in the culture }\end{array}$ & $\begin{array}{l}\text { Normalized } \\
\text { Quantification fator } \\
\text { in the abscess } \times 1000\end{array}$ & $\begin{array}{l}\text { Normalized } \\
\text { Quantification fator } \\
\text { in the culture } \times 1000\end{array}$ & Expression multiplicity \\
\hline \multirow[t]{6}{*}{ Animal 1} & rna16s & 12,213 & $1,693,182$ & & & \\
\hline & nanH & 10,245 & 516,504 & 838,860 & 305,049 & 2750 \\
\hline & Cpp & 7786 & 449,959 & 637,517 & 265,748 & 2399 \\
\hline & Pld & 7203 & 754,682 & 589,781 & 445,718 & 1323 \\
\hline & sodC & 12,990 & 710,035 & $1,063,621$ & 419,349 & 2536 \\
\hline & spaC & 11,330 & 611,099 & 927,700 & 360,917 & 2570 \\
\hline \multirow[t]{6}{*}{ Animal 2} & rna16s & 10,751 & $3,587,966$ & & & \\
\hline & nanH & 14,466 & 843,655 & $1,345,549$ & 235,135 & 5722 \\
\hline & Cpp & 11,368 & 756,508 & $1,057,390$ & 210,846 & 5015 \\
\hline & Pld & 11,753 & 939,822 & $1,093,201$ & 261,937 & 4174 \\
\hline & sodC & 17,348 & $1,055,413$ & $1,613,617$ & 294,154 & 5486 \\
\hline & spac & 14,273 & $1,025,113$ & $1,327,597$ & 285,709 & 4647 \\
\hline \multirow[t]{6}{*}{ Animal 3} & rna16s & 12,109 & $2,490,341$ & & & \\
\hline & nanH & 17,684 & 512,642 & $1,460,401$ & 205,852 & 7094 \\
\hline & Cpp & 13,546 & 429,309 & $1,118,672$ & 172,390 & 6489 \\
\hline & Pld & 15,912 & 460,927 & $1,314,064$ & 185,086 & 7100 \\
\hline & sodC & 20,697 & 577,854 & $1,709,225$ & 232,038 & 7366 \\
\hline & spaC & 20,171 & 601,448 & $1,665,786$ & 241,512 & 6897 \\
\hline \multirow[t]{6}{*}{ Animal 4} & mal6s & 24,930 & $4,981,860$ & & & \\
\hline & nanH & 8376 & 161,958 & 335,981 & 32,510 & 10,335 \\
\hline & Cpp & 7063 & 129,867 & 283,313 & 26,068 & 10,868 \\
\hline & Pld & 7327 & 213,745 & 293,903 & 42,905 & 6850 \\
\hline & sodC & 9982 & 215,407 & 400,401 & 43,238 & 9260 \\
\hline & spac & 8903 & 189,375 & 357,120 & 38,013 & 9395 \\
\hline \multirow[t]{6}{*}{ Animal 5} & rnal6s & 13,377 & $2,012,331$ & & & \\
\hline & nanH & 18,657 & 187,995 & $1,394,707$ & 93,422 & 14,929 \\
\hline & $C p p$ & 15,847 & 196,526 & $1,184,645$ & 97,661 & 12,130 \\
\hline & Pld & 17,692 & 254,409 & $1,322,569$ & 126,425 & 10,461 \\
\hline & sodC & 22,484 & 260,336 & $1,680,795$ & 129,370 & 12,992 \\
\hline & spaC & 20,163 & 292,056 & $1,507,289$ & 145,133 & 10,386 \\
\hline
\end{tabular}

Linear and angular coefficient values obtained from linear regression performed for the cDNA dilution curves of all genes are presented in Additional file 1, which also contains the linear regression line equations, and the formulas used to calculate the quantified variables shown in Table 1.

Average RNAm expression of the five genes expressed in abscesses and cultures varied significantly, as follows: nanH $811.50 \pm 198.27$ and $359.35 \pm 75.45(\mathrm{p}=0.009)$; cpp 856.31 \pm 385.11 and $154.54 \pm 94.34(\mathrm{p}=0.0039) ;$ pld $922.70 \pm 450.73$ and $212.41 \pm 153.10(\mathrm{p}=0.016)$; $\operatorname{sod} C$ $1,293,53 \pm 564.75$ and $223.63 \pm 145.58(\mathrm{p}=0.016)$ and $\operatorname{spaC} 1,157,10 \pm 525.13$ and $214.26 \pm 125.70(\mathrm{p}=0.016)$ (Fig. 2).
The $n a n H, c p p$, pld, sodC and spaC genes were more highly expressed in the abscesses than in the cultures by approximate factors, $8,7,6,7$, and 7 , respectively, according to Table 1 . The relative mean levels of expression of all genes in each animal were: 2.32 (animal 1), 5.01 (animal 2), 6.99 (animal 3), 9.34 (animal 4) and 12.18 (animal 5), respectively. The Kruskal-Wallis test demonstrated that these averages differed statistically, but a larger sample is necessary to clarify whether some biological property is responsible for these findings in the abscesses. No statistical differences were seen in the expression of five genes in the abscess of each animal evaluated separately. Table 1 shows the mean relative transcription values of the five genes, comparing in vivo and in vitro expression. 


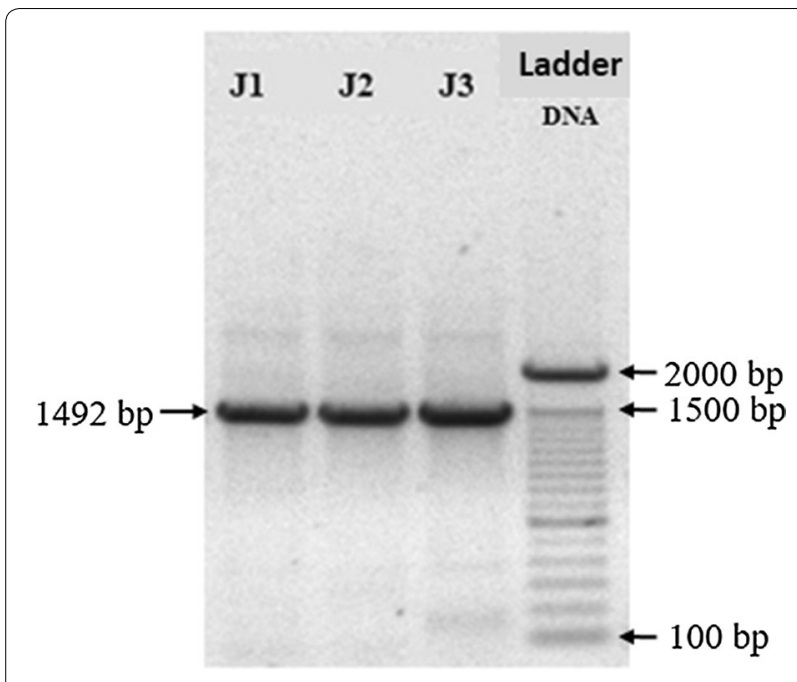

Fig. $21 \%$ agarose gel used to show the 1492 bp bands found in abscess of three animals (J1, J2 and J3) naturally infected by Corynebacterium pseudotuberculosis

\section{Discussion}

mRNA detection of the nanH, cpp, pld, sodC, and spaC genes in bacterial cells obtained from culture indicated that transcription of these genes occurred, in addition to the possible synthesis of the respective proteins. Although it is possible to transcribe genes without the corresponding translation (Houben et al. 2009), in the context of our research, the probability of this occurring in five genes simultaneously is extremely low. Additionally, it is known that the synthesis and secretion of phospholipase D and CP40 proteins in cultures of $C$. pseudotuberculosis occurs, since these substances are detected in culture supernatants (Walker et al. 1994; Wilson et al. 1995). In addition, the interference of phospholipase $\mathrm{D}$ in the attenuation of hemolysis caused by $\beta$-hemolysin from Staphylococcus aureus has been documented in vitro, which serves as an auxiliary test in the identification of C. pseudotuberculosis.

While NanH (neuraminidase $\mathrm{H}$ ) is present on the surface of some bacteria, this enzyme can also be secreted, but this has yet to be proven in C. pseudotuberculosis. The molecular weight of the bacterial neuraminidases can approach $40 \mathrm{kDa}$, or be $80 \mathrm{kDa}$ or more. As previously mentioned, the serum of naturally infected animals contained antibodies against several antigens present in the supernatant of C. pseudotuberculosis cultures.

These antibodies recognize antigens with a molecular weight between 31 and $32 \mathrm{kDa}$, corresponding to phospholipase D (Songer et al. 1990; Linder and Bernheimer 1978), 38-40 kDa, corresponding to CP40 protein (Walker et al. 1994; Wilson et al. 1995) and proteins weighing 20, 24-25, 27-28, 63 and $68 \mathrm{kDa}$, whose structures and functions have yet to be identified (Meyer 2003). Other antigens with molecular weights of 75,85 , 90,108 and $125 \mathrm{kDa}$, initially detected in somatic extracts (Ellis et al. 1991; Braithwaite et al. 1993) were also seen among those secreted when this bacterium was cultured in synthetic media (Paule et al. 2004). Considering the molecular weight range of these unknown antigens weighing from 20 to $125 \mathrm{kDa}$, which is compatible with the molecular weights of some neuraminidases (including $\mathrm{NanH}$ ), it is possible the antibodies present in diseased animals also recognize this enzyme.

The detection of SodC mRNA in bacterial cells cultured in vitro was expected, as all aerobic and aerotolerant bacteria constitutively produce superoxide dismutases when exposed to air or are allowed to grow in environments with molecular oxygen (Dahr et al. 2013). It is not known whether C. pseudotuberculosis secretes this enzyme which, as mentioned previously, is normally present within the cytoplasm, in the periplasmic space of gramnegative bacteria or on the surface of gram-positive cells. When secreted, the molecular weight of SodC expressed by C. pseudotuberculosis ranges between 20 and $125 \mathrm{kDa}$ and is recognized by antibodies from infected animals (Meyer 2003).

$\mathrm{SpaC}$ is a protein located at the tip of the pili of at least three species of corynebacteria (Chang et al. 2011; Zasada et al. 2012; Trost et al. 2010, 2011). In Corynebacterium diphtheriae, SrtA sortase catalyzes the synthesis of the SpaA-type pili, consisting almost exclusively of SpaA pilin, $\mathrm{SpaC}$ adhesin (located at its tip) and secondary pilin called SpaB. SpaA-type pili anchorage is triggered when SrtA sortase incorporates a molecule of $\mathrm{SpaB}$ at the base of the pili by way of lysine-mediated transpeptidation. The final binding step of heteropolymer to murein is mediated by a second sortase, SrtF (Chang et al. 2011). In $C$. diphtheria, there are nine types of genes coding for pilins, located on an island of pathogenicity (Zasada et al. 2012). SpaC adhesin has also been described in C. ulcerans and Corynebacterium pseudotuberculosis (Trost et al. 2010, 2011). The adhesion of $C$. diphtheriae to human pharyngeal epithelial cells is critically dependent on the SpaC protein (Rogers et al. 2011). Given the degree of evolutionary proximity between these species, it is plausible that these three species share similar structure and physiology with respect to the pilli containing $\mathrm{SpaC}$ (Dorella et al. 2006).

From an evolutionary point of view, the advantages obtained by bacterial cells that express these proteins considered virulence factors, or which collaborate in some way to microbial aggressiveness, appears paradoxical with respect to energy. In the case of C. pseudotuberculosis, the gene expression profile while the pathogen is in transit, i.e. outside its natural host, remains unknown. 
Abscesses in the superficial lymph nodes may spontaneously rupture or may be removed by surgical drainage, both situations that favor environmental contamination. Purulent secretions protected from direct sunlight may harbor viable germs for up to 60 days, and no research has been performed on this material to characterize the gene expression profile. To some extent, if virulencerelated molecules are already present in the bacterium while in transit to a host, it could be argued that rapid microbial interference could be facilitated with respect to host innate immunity. Clearly, this does not apply in all situations, since the pathogen may be present in a variety of infectious materials, which may highly differ as to the presence of organic material, dust, degree of hydration, contaminating microbiota, acidity, aeration, among others.

The mRNA expression of genes nanH, pld, sodC, and spaC detected in goat abscesses was expected, since the neuraminidases, phospholipases, superoxide dismutase and adhesins (SodC) are important bacterial virulence factors. The in vivo expression of CP40 serine protease was also expected, considering that antibodies from infected animals recognize this antigen under Western blotting (Walker et al. 1994; Wilson et al. 1995).

Neuraminidase $\mathrm{H}$ mRNA showed the highest relative increase in this study, followed by SodC, CP40, SpaC and phospholipase D mRNAs. It is not possible to definitively define the clinical origin of these differences in gene expression. It is worth noting that all animals selected for sample collection were adults in good physical condition, but the clinical evolution of each animal would be necessary to consider in order to more clearly define clinical origin.

The absence of variation in intra-animal mRNA expression of these genes was unexpected, since there are differences in the involvement of the synthesized molecules with respect to virulence and pathogenesis. The participation of gene transcription regulators may in some way justify this finding. In silico analysis of C. pseudotuberculosis FRC41 revealed the existence of 31 potential regulators of gene transcription (Trost et al. 2010) in this bacterium. Although the strain isolated from goats used in this study is not the that the cited study, it is known that there is great genetic similarity among the different samples sequenced to date.

Accordingly, the sodC gene is part of a regulon that also contains the $\operatorname{sod} \mathrm{A}, \mathrm{ahpC}$ and ahpD genes, which are all controlled by the OxyR transcription factor. However, spaC is not controlled by OxyR, but rather by GlxR, another transcription controller which also influences the transcription of genes nanH and cpp (Trost et al. 2010; Pacheco et al. 2011; Suvorova et al. 2015; Santanajorge et al. 2016).
In sum, the expression of three of the five genes investigated herein could be activated in vivo, probably by way of the same transcription controller, GlxR (Suvorova et al. 2015). Under oxidative stress in animal tissue, the natural expression of the sodC and pld genes appears to be constitutively activated (Hodgson et al. 1999). These considerations may aid in understanding the simultaneous expression of these genes in vivo.

The pld, cpp, nanH, sodC and spaC genes of Corynebacterium pseudotuberculosis were found to transcribed in liquid cultures and in the caseous abscesses of goats, appearing to be constitutively expressed. The transcription of these genes within the abscesses was 6-8 times higher than in culture. No significant differences were detected with respect to the expression of the five genes studied in each animal studied, yet the means of relative gene expression among the tested animals were found to differ significantly. These data require additional confirmation in a larger number of samples, since the sample size herein was limited, thus there was a genetic expression of the bacterium in vitro, but in vivo was better observed so the virulence factors are shown to be important in the pathogenesis of the disease. It is probable that the SodC, NanH and SpaC proteins are also constitutively synthesized and, as the latter two are superficial, it may be of interest to further investigate their applicability as antigenic reinforcement in vaccines against caseous lymphadenitis.

\section{Additional file}

Additional file 1. Linear, angular coefficients, regression equations and formulas for calculating the quantification factors in Table 1.

Authors' contributions

All authors read and approved the final manuscript.

\section{Author details}

${ }^{1}$ Department of Biointeração-Health Sciences Institute, Federal University of Bahia, Salvador, Brazil. ${ }^{2}$ Laboratório de Imunologia e Biologia Molecular, Instituto de Ciências da Saúde, Universidade Federal da Bahia, Avenida Reitor, Miguel Calmon, S/N, Vale do Canela, Salvador, Bahia CEP 40.110-100, Brazil. ${ }^{3}$ Laboratory of Infectology-Prof., Edgard Santos University Hospital, Federal University of Bahia, Salvador, Brazil.

\section{Acknowledgements}

Not applicable.

Competing interests

The authors declare that they have no competing interests.

Availability of data and materials

Not applicable.

Consent for publication

Not applicable. 


\section{Ethics approval and consent to participate}

All applicable international, national and/or institutional guidelines for the care and use of animals were followed.

The caseous materials of used in this study were obtained from goats intended for slaughter. This experiment was conducted under the authority of Brazilian Law n¹1.794, 8 October 2008 (statements on the use of animals in research experiments), after approval by the Secretariat of Animal Health of the Ministry of Agriculture, Livestock and Food Supply. The collection of material was carried out in a slaughterhouse supervised by the National Meat Inspection Service of the same Ministry.

\section{Funding}

Not applicable.

\section{Publisher's Note}

Springer Nature remains neutral with regard to jurisdictional claims in published maps and institutional affiliations.

Received: 18 January 2018 Accepted: 18 April 2018

Published online: 30 May 2018

\section{References}

Arsenault J, Girard C, Dubreuil P, Daignault D, Galarneaeu J, Boisclair J, Simar D, Belanger D (2003) Prevalence of and carcasscondemnation from maedivisna, paratuberculosis and caseous lymphadenitis in culled sheep from Quebec, Canada. Prev Vet Med 59:67-81

Bastos BL, Meyer R, Guimarães JE, Ayres MCC, Guedes MT (2011) Haptoglobin, fibrinogen concentrartions and Leukocyte counts in the clinical investigation of caseous lymphadenitis in sheep. Vet Clin Pathol 40:496-503

Batey RG (1986) Frequency and consequence of caseous lymphadenitis in sheep and lambs slaughtered at a Western Australian abattoir. Am J Vet Res 47:482-487

Braithwaite CE, Smith EE, Songer JG, Reine AH (1993) Characterization of detergent-soluble proteins of Corynebacterium pseudotuberculosis. Vet Microbiol 38:59-70

Brown CC, Olander HJ (1987) Caseous lymphadenitis of goats and sheep: a review Vet Bulletin 57:1

Carvalho DM, de Sá PH, Castro TLP, Pinto A, Gil DJP, Bagano P, Bastos B, Costa LFM, Meyer R, Silva A, Azevedo V, Ramos RTJ, Pacheco LGC (2014) Reference genes for RT-qPCR studies in Corynebacterium pseudotuberculosis identified through analysis of RNA-seq data. Anton Van Leeuw 106:605-614

Chang C, Mandlik A, Das A, Ton-that H (2011) Cell surface display of minor pilin adhesins in the form of a simple heterodimeric assembly in Corynebacterium diphtheriae. Mol Microbiol. https://doi.org/10.111 1/j.1365-2958.2010.07515.x

Dahr MS, Gupta V, Virdi JS (2013) Detection, distribution and characterization of novel superoxide dismutases from Yersinia enterocolitica Biovar 1A. PLoS One 8(5):1-12

Dorella FA, Estevam EM, Pacheco LGC, Guimarães CT, Lana UGP, Gomes EA Barsante MM, Oliveira SC, Meyer R, Miyoshi A, Azevedo V (2006) In vivo insertional mutagenesis in Corynebacterium pseudotuberculosis: an efficient means to identify DNA sequences encoding exported proteins. Appl Environ Microbiol 72:7368-7372

Ellis JA, Hawk DA, Mills KW, Pratt DL (1991) Antigen specificity and activity of ovine antibodies induced by immunization with Corynebacterium pseudotuberculosis culture filtrate. Vet Immunol Immunopathol 28:303-319

Guimarães AS, Carmo FB, Heinemann MB, Portela RW, Meyer R, Lage AP, Seyffert N, Miyoshi A, Azevedo V, Gouveia AM (2011) High sero-prevalence of caseous lymphadenitis identified in slaughterhouse samples as a consequence of deficiencies in sheep farm management in the state of Minas Gerais, Brazil. BMC Vet Res. https://doi.org/10.1186/1746-6148-7-68

Hodgson ALM, Carter K, Tachedjian M, Krywult J, Corner LA, Mccoll M, Cameron A (1999) Efficacy of an ovine caseous lymphadenitis vaccine formulated using a genetically inactive form of the Corynebacterium pseudotuberculosis, phospholipase D. Vaccine 17:802-808
Houben E, Walburger A, Ferrari G, Nguyen L, Thompson CJ, Miess C, Vogel G, Mueller B, Pieters J (2009) Differential expression of a virulence factor in pathogenic and non-pathogenic mycobacteria. Mol Microbiol. https:// doi.org/10.1111/j.1365-2958.2009.06612.x

Kumar J, Tripathi BN, Kumar R, Sonawane GG, Dixit SK (2013) Rapid detection of Corynebacterium pseudotuberculosis in clinical samples from sheep. Trop Anim Health Prod 45:1429-1464

Linder R, Bernheimer AW (1978) Effect of sphingomyelin-containing liposomes of phospholipase D from Corynebacterium ovis and the cytolysin from Stoichactis helianthus. Biochim Biophys Acta 530:236-246

Meyer R (2003) Corynebacterium pseudotuberculosis e o hospedeiro caprino: aspectos da prevalência, do diagnóstico e da imunidade. Tese, Instituto de Ciências da Saúde, Universidade Federal da Bahia, Salvador

Middleton MJ, Epstein VM, Gregory GG (1991) Caseous lymphadenitis on Flinders Island: prevalence and management surveys. Aust Vet J 69:311-313

Nascimento DL (2012) Soroepidemiologia da Linfadenite Caseosa em ovinos de raça definida do estado da Bahia e correlação com a ocorrência de outras doenças infecciosas e com aspectos zootécnicos. Dissertação (Mestrado em Ciência Animal Nos Trópicos)_-Instituto de Ciências da Saúde, Universidade Federal da Bahia, Salvador, p 91

Pacheco LG, Slade SE, Seyffert N, Santos AR, Castro TLP, Silva W, Santos AV, Santos SG, Farias LM, Carvalho MAR, Pimenta A, Meyer R, Scrivens JH, Oliveira SC, Miyoshi A, Dowson CG, Azevedo V (2011) A combined approach for comparative exoproteome analysis of Corynebacterium pseudotuberculosis. BMC Microbiol 11:12

Paule B, Meyer R, Moura-costa LF, Bahia RC, Carminati R, Regis LF, Vale VL, Freire SM, Nascimento I, Schaer R, Azevedo V (2004) Three phase partitioning as an efficient method for extraction/concentration of immunoreactive excreted-secreted proteins of Corynebacterium pseudotuberculosis. Prot Express Purif 34:311-317

Petri WA, Mann BJ, Huston CD (2010) Microbial adherence. In: Mandell GL, Bennett JE, Dolin R (eds) Mandell, Douglas, and Bennett's Principles and Practice of Infectious Diseases, 7th edn. Philadelphia, Churchill Livinston Elsevier

Rogers EA, Das A, Ton-that H (2011) Adhesion by pathogenic corynebacteria. Adv Exp Med Biol. https://doi.org/10.1007/978-94-007-0940-9_6

Sá MCA, Veschi JLA, Santos GB, Amanso ES, Oliveira SAS, Mota RA, VeneroniGouveia G, Costa MM (2013) Activity of disinfectants and biofilm production of Corynebacterium pseudotuberculosis. Pesqui Vet Bras 33(11):1319-1324

Sanjay MK, Shrideshikan SM, Usha MS, Philipraj A, Gaddad SM, Shivannavar CT (2010) Detection, amplification and sequence homology of sodC in clinical isolates of Salmonella spp. Indian J Med Res 131:565-570

Santana-Jorge KT, Santos TM, Tartaglia NR, Aguiar EL, Souza RF, Mariutti RB, Eberle RJ, Arni RK, Portela RW, Azevedo V (2016) Putative virulence factors of Corynebacterium pseudotuberculosis FRC41: vaccine potential and protein expression. Microb Cell Fact 15(1):83

Songer JG, Libby SJ, landolo JJ, Cuevas WA (1990) Cloning and expression of the phospholipase D gene from Corynebacterium pseudotuberculosis in Escherichia coli. Infect Immun 58:131-137

Souza MF, Carvalho AA, Garino F Jr, Riet-Correa F (2011) Linfadenite caseosa em ovinos deslanados abatidos em um frigorífico da Paraíba. Pesqui Vet Bras 31(3):224-230

Stoops SG, Renshaw HW, Thilsted JP (1984) Ovine caseous lymphadenitis: disease prevalence, lesion distribution, and thoracic manifestations in a population of mature culled sheep from western United States. Am J Vet Res 45:557-561

Suo Y, Huang Y, Liu Y, Shi C, Shi X (2012) The expression of superoxide dismutase (SOD) and a putative transporter permease is inversely correlated during biofilm formation in Listeria monocytogenes $4 \mathrm{~b}$ G. PLOS ONE. https ://doi.org/10.1371/journal.pone.0048467

Suvorova IA, Korostelev YD, Gelfand MS (2015) GntR family of bacterial transcription factors and their DNA binding motifs: structure, positioning and co-evolution. PLoS ONE 10(7):21

Trost E, Ott L, Schneider J, Schröder J, Jaenicke S, Goesmann A, Husemann P, Stoye J, Dorella FA, Rocha FS, Soares SC, D'afonseca V, Miyoshi A, Ruiz J, Silva A, Azevedo V, Burkovski A, Guiso N, Join-lambert OF, Kayal S, Tauch A (2010) The complete genome sequence of Corynebacterium pseudotuberculosis FRC41 isolated from a 12-year-old girl with necrotizing lymphadenitis reveals insights into gene-regulatory networks contributing to virulence. BMC Genom. https:/doi.org/10.1186/1471-2164-11-728 
Trost E, Al-dilaimi A, Papavasiliou P, Schneider J, Viehoever P, Burkovski A, Soares SC, Almeida SS, Dorella FA, Miyoshi A, Azevedo V, Schneider MP, Silva A, Santos CS, Santos LS, Sabbadini P, Dias AA, Hirata R Jr, MattosGuaraldi AL, Tauch A (2011) Comparative analysis of two complete Corynebacterium ulcerans genomes and detection of candidate virulence factors. BMC Genom. https://doi.org/10.1186/1471-2164-12-383

Unanian MM, Feliciano-Silva AED, Pant KP (1985) Abscesses and caseous lymphadenitis in goats in tropical semi-arid northeast Brazil. Trop Anim Health Prod 17(1):57-62

Walker J, Jackson HJ, Eggleton DG, Meeusen EN, Wilson MJ, Brandon MR (1994) Identification of a novel antigen from Corynebacterium pseudotuberculosis that protects sheep against caseous lymphadenitis. Infect Immun 62:2562-2569

Wilson MJ, Brandon MR, Walker J (1995) Molecular and biochemical characterization of a protective 40-kilodalton antigen from Corynebacterium pseudotuberculosis. Infect Immun 63:206-217

Windsor PA (2011) Control of caseous lymphadenitis. Vet Clin North Am Food Anim Pract 27:193-202

Zasada AA, Formińska K, Rzeczkowska M (2012) Occurence of pili genes in Corynebacterium diphtheriae strains. Med Dosw Mikrobiol 64:19-27

\section{Submit your manuscript to a SpringerOpen ${ }^{\circ}$ journal and benefit from:}

- Convenient online submission

- Rigorous peer review

- Open access: articles freely available online

- High visibility within the field

- Retaining the copyright to your article

Submit your next manuscript at $\boldsymbol{\nabla}$ springeropen.com 